\title{
Influence of combination forms of intact sub-layer and tectonically deformed sub-layer of coal on the gas drainage performance of boreholes: a numerical study
}

\author{
Wei Zhao ${ }^{1,2,4} \cdot$ Kai Wang ${ }^{1,2} \cdot$ Rong Zhang $^{3} \cdot$ Huzi Dong $^{1,2} \cdot$ Zhen $_{\text {Lou }}{ }^{1,2}$ • \\ Fenghua $\mathrm{An}^{4}$
}

Received: 11 January 2020/Revised: 12 February 2020/Accepted: 2 April 2020/Published online: 24 April 2020

(C) The Author(s) 2020

\begin{abstract}
High concentration and large flow flux of gas drainage from underground coal seams is the precondition of reducing emission and large-scale use of gas. However, the layered occurrence of coal seams with tectonically deformed sub-layers and intact sub-layers makes it difficult to effectively drain gas through commonly designed boreholes. In this study, the gas drainage performance in coal seams with different combinations of tectonically deformed sub-layers and intact sub-layers was numerically analyzed. The analysis results show that the gas drainage curve changes from a singlestage line to a dual-stage curve as the permeability ratios of Zone II $\left(k_{\mathrm{II}}\right)$ and Zone I $\left(k_{\mathrm{I}}\right)$ increase, raising the difficulty in gas drainage. Furthermore, a dual-system pressure decay model based on the first-order kinetic model was developed to describe the dual-stage characteristics of pressure decay curves with different permeability ratios. In the end, the simulation results were verified with reference to in-situ drainage data from literature. The research results are helpful for mines, especially those with layered coal seams comprising tectonically deformed sub-layers and intact sub-layers, to choose appropriate gas drainage methods and develop the original drainage designs for achieving better gas drainage performance.
\end{abstract}

Keywords Tectonically deformed coal $\cdot$ Pressure decay $\cdot$ Permeability $\cdot$ Hydraulic flushing boreholes

\section{Introduction}

Tectonically deformed coal is the coal whose chemical and mechanical properties have been dramatically altered by tectonic movements (Cheng and Pan 2020; Ju et al. 2014). Different from intact coal, it is usually characterized by a

Kai Wang

kaiwang@cumtb.edu.cn

$1 \quad$ Beijing Key Laboratory for Precise Mining of Intergrown Energy and Resources, China University of Mining \& Technology, Beijing, Beijing 100083, China

2 School of Emergency Management and Safety Engineering, China University of Mining \& Technology, Beijing, Beijing 100083, China

3 Flight Technology College, Civil Aviation University of China, Tianjin 300300, China

4 State Key Laboratory Cultivation Base for Gas Geology and Gas Control (Henan Polytechnic University), Jiaozuo 454003, China higher gas content, a higher gas desorption rate, a lower mechanical strength and a lower permeability (Black 2019; Wang et al. 2015; Wu et al. 2019; Zhao et al. 2015, 2019; Zhi and Elsworth 2016). Tectonically deformed coal is widely distributed in China, specifically, in the west of Henan Province, the south of Shanxi Province and the middle and north of Anhui Province, etc., where intense tectonic movements occurred during coal formation. According to the statistics, there are about 457 billion tons of tectonically deformed coal resources in China and up to $23.5 \%$ of coal production is from tectonically deformed coal seams (Cheng and Pan 2020).

The layered structure of coal seams comprising tectonically deformed sub-layers and intact sub-layers is often found in actual geological occurrence of coal ( $\mathrm{Lu}$ et al. 2019a, b). Tectonically deformed coal seams caused by regional bedding sliding generally possess the combined vertical "intact-tectonically deformed-intact" layered structure (e.g., Daning Coal Mine in Shanxi Province) (Lu et al. 2019a, b) or "intact-tectonically deformed-intact" 
layered structure (e.g., Guhanshan Coal Mine in Henan Province) (Geological Report of Guhanshan Mine 2015; Zhang et al. 2019). In contrast, those caused by local faults tend to own an integrated continuous region of tectonically deformed coal around the fault areas (Fig. 1). The different combinations of tectonically deformed coal and intact coal results in their varying difficulty degrees of gas drainage. Therefore, commonly used original unified gas drainage methods like boreholes along the seam should be modified accordingly by amending parameters such as gas drainage time, gas drainage pressure and borehole spacing.

In this study, layered coal seams comprising tectonically deformed sub-layers and intact sub-layers were taken as the research object. Three combined permeability forms, "high-low-high", "equal" and "low-high-low" representing "intact-tectonically deformed-intact", "intact" and "intact-tectonically deformed-intact" coal combinations, respectively, were considered. Besides, based on the proposed constitutive equations, the gas pressure distribution and gas drainage curve were numerically analyzed and verified by the actual drainage data. The results obtained are helpful to the design of gas drainage boreholes and the prevention of outbursts in coal seams with tectonically deformed sub-layers.

\section{Constitutive equations}

\subsection{Equation of gas diffusion in matrixes}

Coal is generally regarded as a heterogeneous dual-porosity medium consisting of matrixes and fractures (Fan and Liu 2018, 2019; Pan et al. 2010), and it is often simplified into an aggregation of sheets, match sticks and cubes in the simulation of gas transport in coal (Liu and Harpalani
2013). According to the sequence of gas transport, gas transports in coal by three steps: gas desorption from matrix surface to matrix pores, gas diffusion from matrix pores to fractures and gas flow in fractures.

In matrixes, gas exists in two states, namely the adsorbed state and the free state, of which the former obeys the Langmuir law, as written in Eq. (1):

$X_{\mathrm{x}}=\frac{a b p_{\mathrm{m}}}{1+b p_{\mathrm{m}}}$

where, $a$ is the gas adsorption capacity of coal, i.e. the Langmuir volume; $b$ is the reciprocal of Langmuir pressure; $p_{\mathrm{m}}$ is the gas pressure in matrixes; and $X_{\mathrm{x}}$ is the gas adsorption amount.

The amount of free gas conforms to the following relationship:

$X_{\mathrm{y}}=\frac{\phi_{\mathrm{m}} p_{\mathrm{m}}}{\rho p_{0}}$,

where, $X_{\mathrm{y}}$ is the free gas content; $\phi_{\mathrm{m}}$ is the matrix porosity; $p_{0}$ is the ambient gas pressure; and $\rho$ is the gas density at standard temperature and pressure (STP).

The average gas concentration in matrixes is:

$\bar{c}_{\mathrm{m}}=\frac{X_{\mathrm{x}}+X_{\mathrm{y}}}{V_{\mathrm{m}}}=\left(\frac{a b p_{\mathrm{m}}}{1+b p_{\mathrm{m}}}+\frac{\phi_{\mathrm{m}} p_{\mathrm{m}}}{\rho p_{0}}\right) \cdot \frac{\rho \mathrm{M}}{V_{\mathrm{m}}}$,

where, $\bar{c}_{\mathrm{m}}$ is the average gas concentration in matrixes; $V_{\mathrm{m}}$ is the matrix volume; and $M$ is the molar mass of gas.

According to the Fick's description, diffusion is a mass transfer process driven by gas concentration difference:

$q_{\mathrm{m}}=D \tau V_{\mathrm{m}}\left(\bar{c}_{\mathrm{m}}-c_{\mathrm{f}}\right)$

where, $q_{\mathrm{m}}$ is the mass flux; $D$ is the diffusion coefficient; $\tau$ is the shape factor of matrixes; and $c_{\mathrm{f}}$ is the gas concentration in fractures.

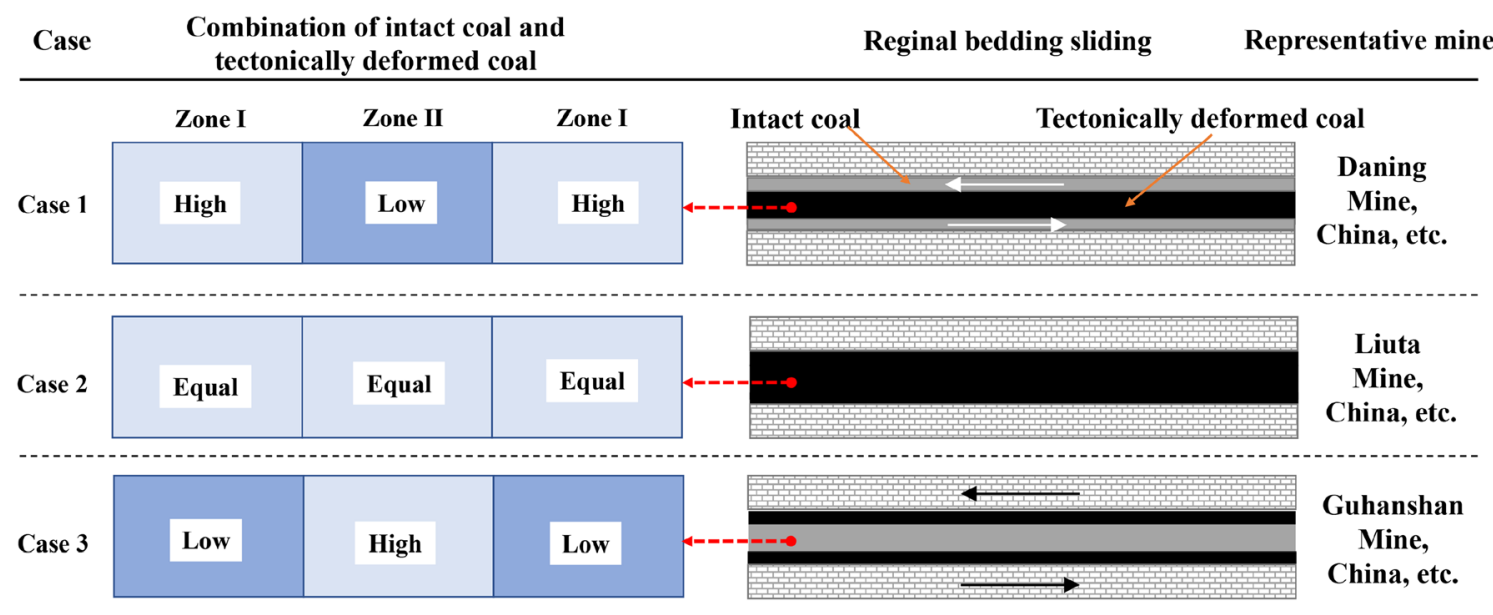

Fig. 1 Typical combination forms of intact-tectonically deformed coal (Zhang et al. 2019; Lu et al. 2019a, b; Geological Report of Guhanshan Mine 2015) 
Gas pressure and gas concentration can be interconverted using the equation of state of real gas:

$$
\left\{\begin{aligned}
c_{\mathrm{m}} & =\frac{M}{Z_{\mathrm{m}} R T} p_{\mathrm{m}} \\
c_{\mathrm{f}} & =\frac{M}{Z_{\mathrm{f}} R T} p_{\mathrm{f}}
\end{aligned}\right.
$$

where, $p_{\mathrm{f}}$ is the gas pressure in fractures; $Z_{\mathrm{m}}$ and $Z_{\mathrm{f}}$ whose values can be assumed to be 1 are the coefficients of compressibility for gas in matrixes and fractures, respectively; $R$ is universal gas constant, $8.314 \mathrm{~J} /(\mathrm{mol} \mathrm{K})$; and $T$ is the gas temperature, $\mathrm{K}$.

Hence, Eq. (6) can be obtained by integrating Eq. (4) with Eq. (5):

$q_{\mathrm{m}=\frac{D \tau M V_{\mathrm{m}}}{R T}\left(p_{\mathrm{m}}-p_{\mathrm{f}}\right)}$

Gas in matrixes diffuses into fractures, and the mass conservation equation of gas in matrixes is:

$q_{\mathrm{m}}=-\frac{\partial \bar{c}_{\mathrm{m}} V_{\mathrm{m}}}{\partial t}$

Equation (8) can be obtained by substituting Eqs. (3) and (6) into Eq. (7):

$\frac{\partial p_{\mathrm{m}}}{\partial t}=-\frac{D \tau\left(p_{\mathrm{m}}-p_{\mathrm{f}}\right)}{\left(\frac{a b}{1+b p_{\mathrm{m}}}-\frac{a b^{2} p_{\mathrm{m}}}{\left(1+b p_{\mathrm{m}}\right)^{2}}+\frac{\phi_{\mathrm{m}}}{\rho p_{0}}\right) \frac{\rho R T}{V_{\mathrm{m}}}}$

\subsection{Equation of gas flow in fractures}

Gas flow in fractures is widely believed to obey the Darcy law (Pan et al. 2010), which can be expressed as:

$v_{\mathrm{g}}=\frac{k_{\mathrm{f}}}{\mu} \nabla p_{\mathrm{f}}$

where, $v_{\mathrm{g}}$ is the gas flow rate; $k_{\mathrm{f}}$ is the gas permeability; and $\mu$ is the gas dynamic viscosity.

On the one hand, gas in fractures will leave fractures due to the pressure difference; on the other hand, gas in matrixes will supply free gas to fractures due to gas desorption and diffusion. Thus, the mass conservation equation of gas in fractures can be written as:

$\frac{\partial m_{\mathrm{f}}}{\partial t}-\nabla \cdot\left(\rho v_{\mathrm{g}}\right)=q_{\mathrm{m}}$

where, $m_{\mathrm{f}}$ is the mass of free gas in fractures.

Substituting Eqs. (6) and (9) into Eq. (10), the governing equation for gas flow in fractures can be obtained:

$$
\begin{aligned}
\phi_{\mathrm{f}} & \frac{\partial\left(p_{\mathrm{f}}\right)}{\partial t}+p_{\mathrm{f}} \frac{\partial\left(\phi_{\mathrm{f}}\right)}{\partial t}-\frac{k}{\mu} \nabla \cdot\left(p_{\mathrm{f}} \cdot \nabla p_{\mathrm{f}}\right)-D \tau \\
& \cdot\left(1-\phi_{\mathrm{f}}\right)\left(p_{\mathrm{m}}-p_{\mathrm{f}}\right) \\
& =0
\end{aligned}
$$

where, $\phi_{\mathrm{f}}$ is the fracture porosity.
The above constitutive equations can be interconnected with the aid of the PDE module in COMSOL Multiphysics (Fig. 2).

\section{Geometric model and boundary setting}

Based on the three cases listed in Fig. 1, a simplified geometric model was established (Fig. 3). The model contains two sections, Zone I and Zone II, representing areas with drainage boreholes and areas without drainage boreholes, respectively. The combination type of intact coal and tectonically deformed coal is realized by changing coal permeability in Zones I and II. The permeability ratios of coal in Zones II and I $\left(k_{\mathrm{II}} / k_{\mathrm{I}}\right)$ are $0.1,1$ and 10 for Cases 1,2 and 3 , respectively. The geometric model is a $3-\mathrm{m}$-long and 1-m-high rectangle whose boundaries were set to be zero flux. In addition, a borehole with the diameter of $100 \mathrm{~mm}$ was arranged in Zone II, and its boundaries were set to be $-13 \mathrm{kPa}$ pressure. After the simulation, the drainage curve of gas mass was plotted by taking the integral of gas pressure difference in the studied area. Moreover, Line $O O^{\prime}(0,0.25 ; 3,0.25)$ and Point $A(1,0.5)$ were set to monitor the local change of gas pressure. It is noteworthy that the mechanical module was not introduced into the simulation because the permeability ratio $\left(k_{\mathrm{II}} / k_{\mathrm{I}}\right)$ needs to be constant for comparison. All the physical parameters used are given in Table 1.

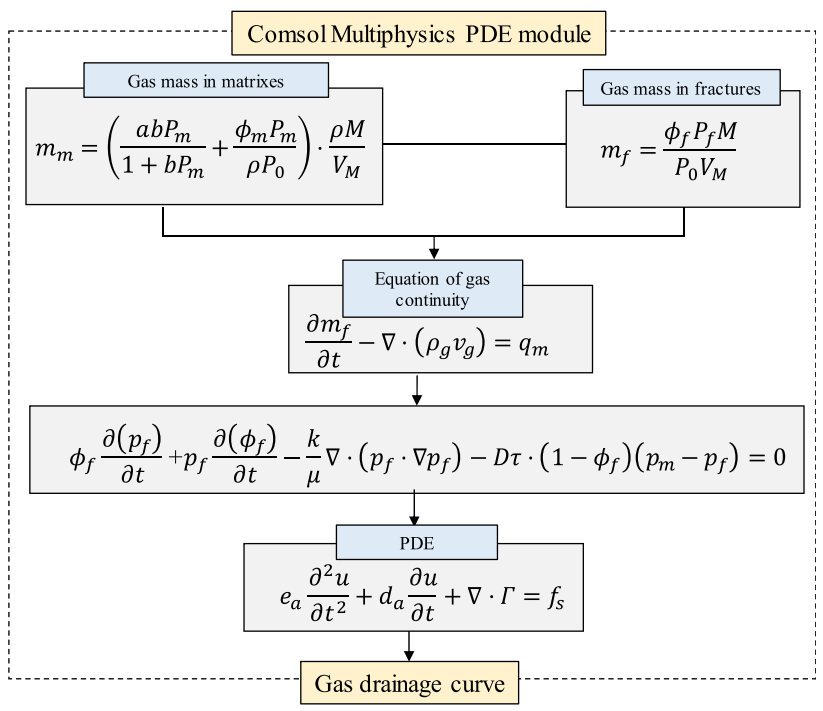

Fig. 2 Constitutive equations 


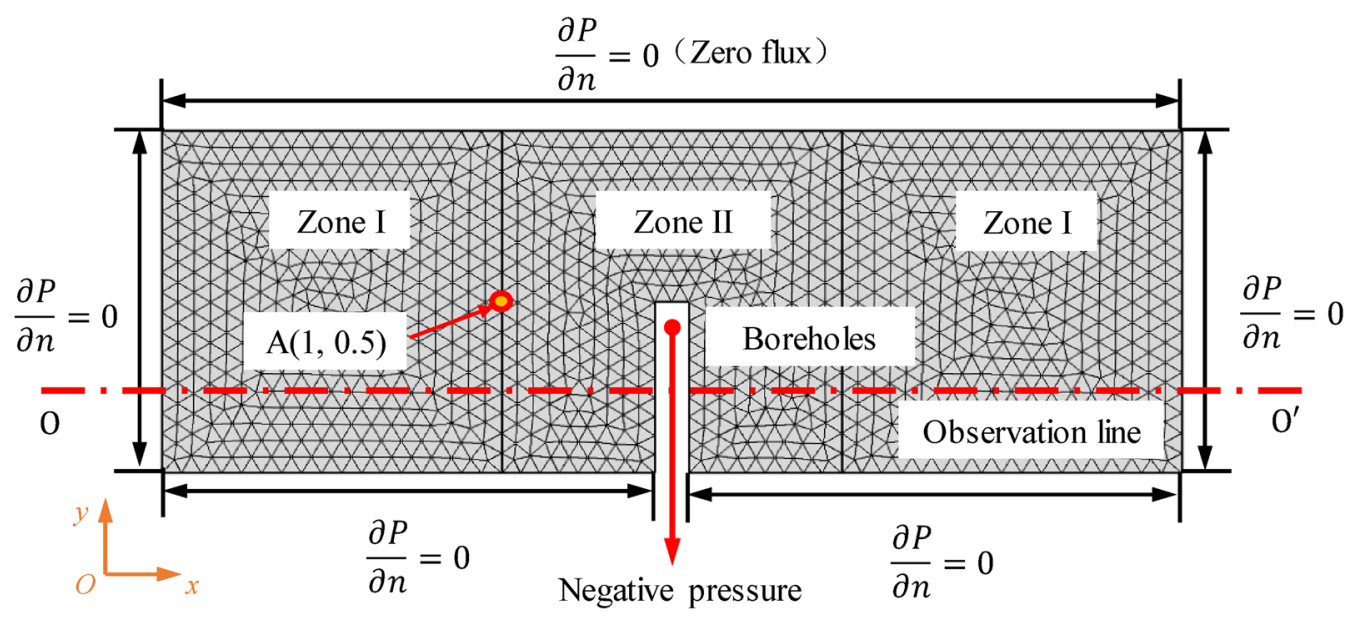

Fig. 3 Simplified geometric model and boundary settings

Table 1 Parameter settings (An et al. 2013; Gong et al. 2019)

\begin{tabular}{llll}
\hline Physical meaning & Value & Physical meaning & Value \\
\hline Adsorption volume $a$ & $45 \mathrm{~m}^{3} / \mathrm{t}$ & Adsorption constant $b$ & $1.3 \mathrm{MPa}^{-1}$ \\
Coal false density & $1.35 \mathrm{t} / \mathrm{m}^{3}$ & Initial permeability & $3.0 \times 10^{-19} \mathrm{~m}^{2}$ \\
Gas density at STP & $0.716 \mathrm{~kg} / \mathrm{m}^{3}$ & Molar mass of methane & $16 \mathrm{~g} / \mathrm{mol}$ \\
Gas dynamic viscosity & $1.08 \times 10^{-5} \mathrm{~Pa} \mathrm{~S}$ & Drainage pressure & $-13 \mathrm{kPa}$ \\
Initial gas pressure & $2.0 \mathrm{MPa}$ & Fracture porosity & 0.00804 \\
Matrix porosity & 0.05 & Universal gas constant & $8.314 \mathrm{~J} /(\mathrm{mol} \mathrm{K})$ \\
Temperature & $303 \mathrm{~K}$ & Molar volume & $22.4 \mathrm{~L} / \mathrm{mol}$ \\
\hline
\end{tabular}

\section{Result and discussion}

\subsection{Overall gas pressure distributions with different permeability ratios $k_{\mathrm{II}} / k_{\mathrm{I}}$}

Figure 4 displays the simulation results of overall gas pressure with different permeability ratios under the same drainage pressure. In Case 1 where $k_{\mathrm{II}} / k_{\mathrm{I}}=0.1$, gas pressure mainly decreases around the borehole in Zone II, exhibiting a clear lamp-cover-shaped distribution, while no obvious gas pressure gradient is obtained in the high-permeability coal in Zone I (with the same color). Regarding Case 2 where $k_{\mathrm{II}} / k_{\mathrm{I}}=1$, the area of pressure decay expands from Zone I to Zone II. An obvious gas pressure gradient appears in Zone II, which is similar to results of gas pressure distribution in homogeneous coal with a single borehole. In contrast, Case 3 where $k_{\mathrm{II}} / k_{\mathrm{I}}=10$ demonstrates a more obvious partition property than Cases 1 and 2 . In this case, the blue area expands dramatically in Zone II, indicating the formation of a larger range of gas pressure decay compared with the previous cases. However, because of the low permeability in Zone I, the rate of gas pressure decay decelerates in Zone I, forming a clear strip-shaped gas pressure distribution. Considering the range of gas pressure decay, it can be concluded that the "low-highlow" permeability combination described in Case 3 brings about the best gas drainage performance, whereas the "high-low-high" permeability combination described in Case 1 leads to the greatest difficulty in gas drainage.

\subsection{Local gas pressure distributions with different permeability ratios $k_{\mathrm{II}} / k_{\mathrm{I}}$}

Figure 5 presents the simulation results of gas pressure distribution at Line $O O^{\prime}$ for 50, 100, 150 and 200 days, respectively. It can be found that the local pressure distributions in the three cases resemble the overall results displayed in Fig. 4 . In Case 1 where $k_{\mathrm{II}} / k_{\mathrm{I}}=0.1$, the gas pressure decay area mainly concentrates around the borehole. Specifically, the shapes of gas pressure decay in Zone I are nearly parallel straight lines, while those in Zone II are curved lines with high tangency slopes. The reason is as follows: Due to the much lower permeability of coal in Zone II, gas can hardly be desorbed from the coal and 


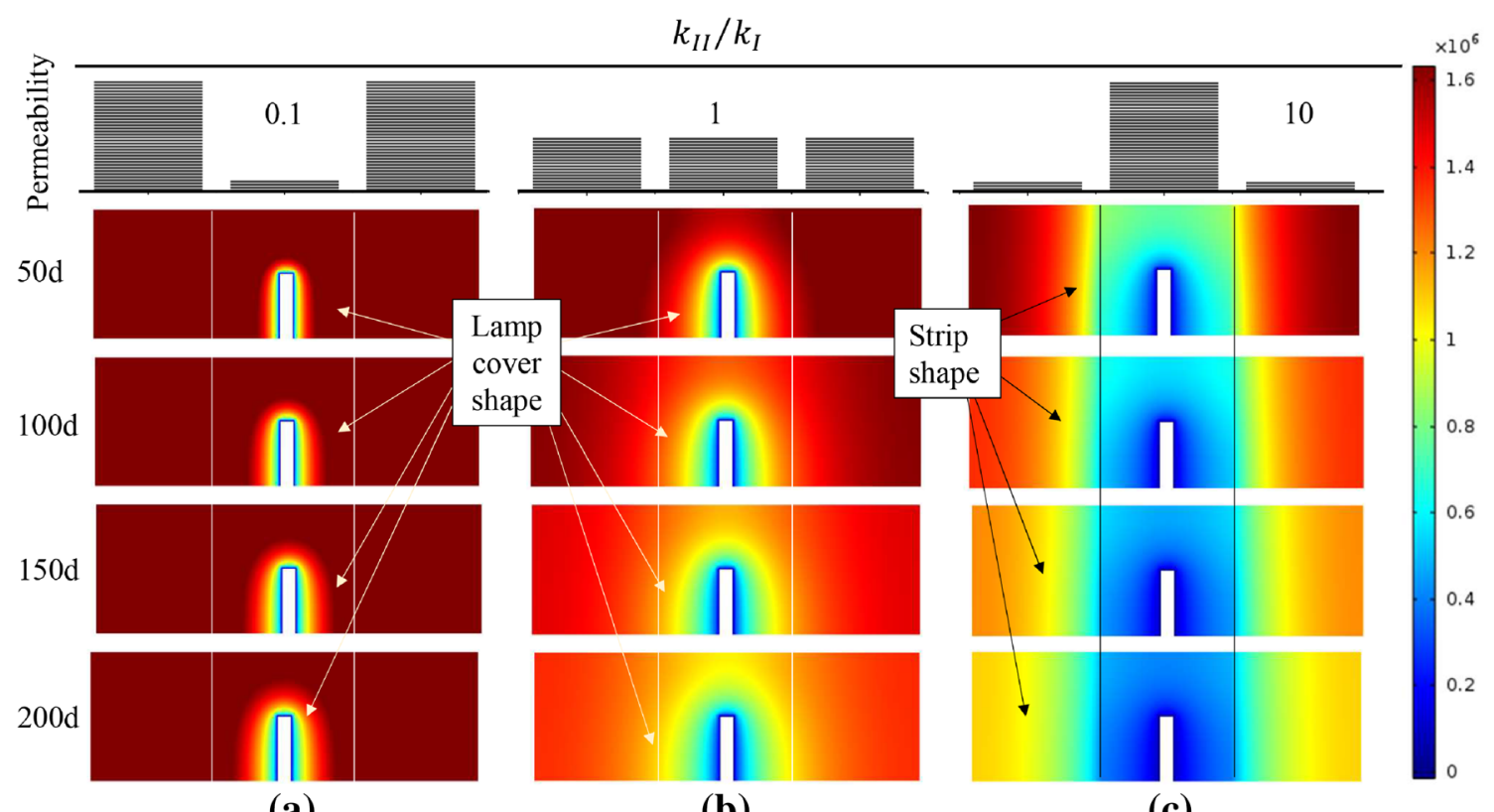

(a)

(b)

(c)

Gas pressure cloud map

Fig. 4 Cloud map of gas distribution in the whole area

remains at a high pressure for a long time. On the contrary, gas in the low-permeability coal in Zone I can easily move away from fractures, resulting in a small pressure gradient and straight lines of gas pressure decay along the $x$ axis. In Case 2 where $k_{\mathrm{II}} / k_{\mathrm{I}}=1$, no obvious partition signs are observed, and the gas pressure distribution curves are relatively smooth in a single-butterfly shape along the $x$ axis. In Case 3 where $k_{\mathrm{II}} / k_{\mathrm{I}}=10$, a clear partition line exists between Zone I and Zone II. In each zone, the curves are distributed in a dual-butterfly shape along the $x$ axis. The reason is as follows: Gas in the high-permeability coal in Zone II can easily move away, but Zone I fails to supply gas to Zone II in time owing to its lower permeability. Eventually, a discontinuous pressure distribution different from the one in Case 2 is formed. Hypothetically, Zone II acts as a borehole with an expanded diameter of $1 \mathrm{~m}$ which is much larger than the initially set diameter $(100 \mathrm{~mm})$ of the simulated borehole. Hence, the pressure distribution is supposed to feature dual stages, consisting of pressure decay curves for a smaller borehole and a hypothetical larger borehole.

The roles of Zone I and II in gas pressure distribution curves can be obtained in light of the theory of water transport through pipes. In Case 1, Zone II acts as a valve that limits the "water flux" from Zone I. It determines the maximum flow rate of gas and thus is the main controller in this situation (Fig. 5d). On the contrary, if the "water flux" cannot reach the maximum flux that pipes can provide, which may result in an under-voltage phenomenon, the main controller would be the water flux itself. As a result, in Case 3, Zone I should be the main controller of gas flow (Fig. 5f). In Case 2, the roles of Zone I and Zone II are ideally matched, which means the actual water flux basically equals the maximum water flux that the valve can provide. In this situation, Zone 1 and Zone II equally control the gas flow (Fig. 5e).

\subsection{Gas drainage curves with different permeability ratios $k_{\mathrm{II}} / k_{\mathrm{I}}$}

To better illustrate the variation of gas drainage volume with time, the pressure at Point $A(1,0.5)$ was monitored during simulation (Fig. 6a). It can be found that the decreasing rate and range of residual pressure at Point $A$ both rise with the increase of $k_{\mathrm{II}} / k_{\mathrm{I}}$. The relationship between the gas drainage volume and the time varies from a straight line to a dual-stage curve consisting of a fast pressure-decay curve and a slow one.

The first-order kinetic model is extensively employed to describe the gas desorption behavior of coal (Airey 1968):

$M(t)=M_{\infty} \exp (-k t)$,

where, $M(t)$ and $M_{\infty}$ are the amounts of desorbed gas mass at times $t$ and $t_{\infty}$, respectively; $k$ is the first-order kinetic model constant; and $t$ is the time. 


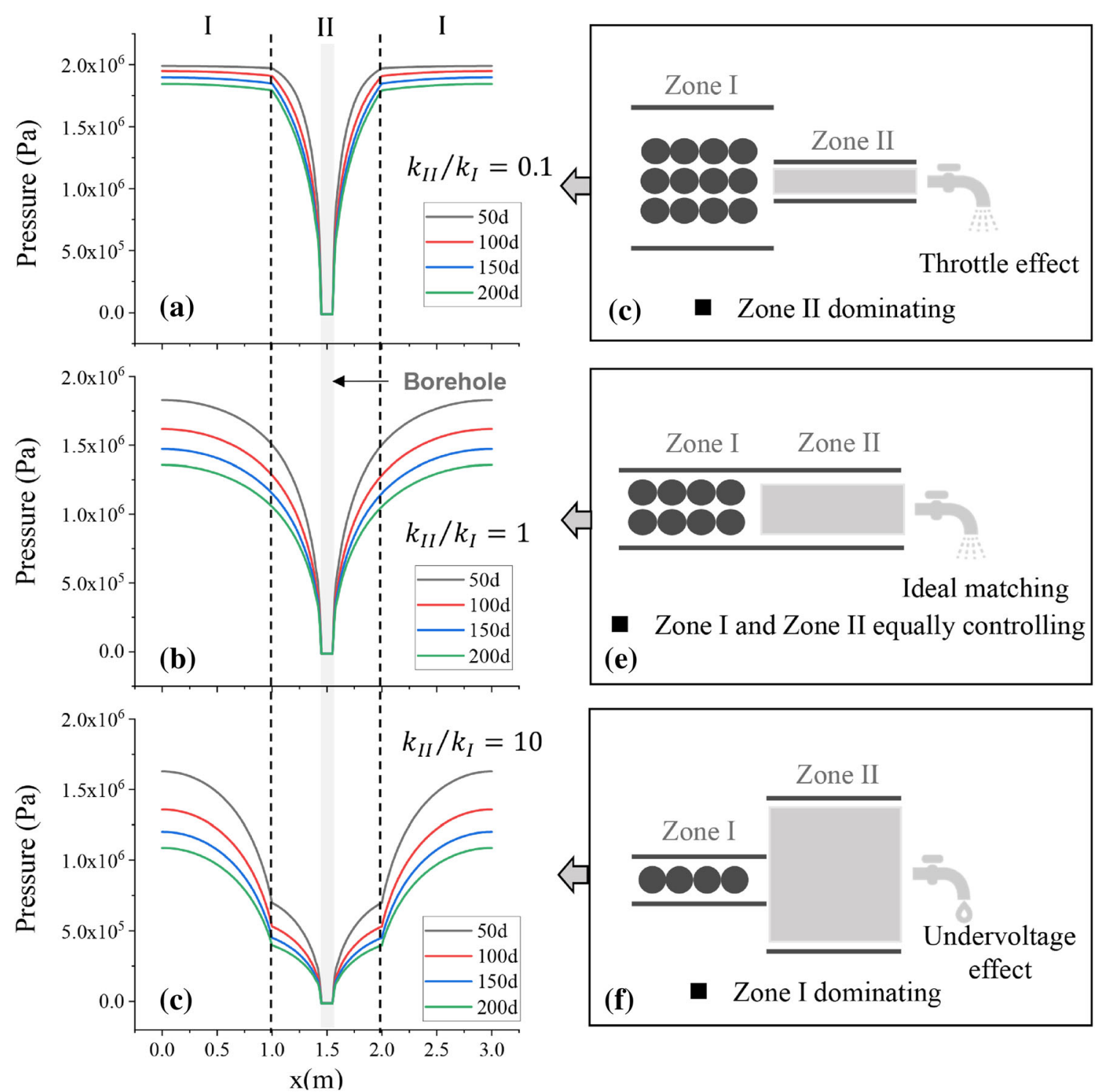

Fig. 5 Gas pressure distribution curves at Line $O O^{\prime}$

Similar to the mass-based first-order kinetic model, a pressure-based first-order kinetic model Eq. (13) is established based on the equation of state of gas (Busch et al. 2004; Zhao et al. 2014):

$P(t)-P_{\infty}=\left(P_{0}-P_{\infty}\right) \exp (-k \cdot t)$,

where, $P(t), P_{0}$ and $P_{\infty}$ are the gas pressures at times $t, t_{0}$ and $t_{\infty}$, respectively. Equations (11) and (12) are appropriate for describing gas desorption in a single uniform system. If the gas pressure variation is characterized by dual systems, i.e. tectonically deformed coal and intact coal, Eq. (13) can be evolved into Eq. (14):

$$
\begin{aligned}
Q_{r}(t) & =\frac{P(t)-P_{\infty}}{P_{0}-P_{\infty}}=\frac{P_{1}(t)+P_{2}(t)-P_{1 \infty}-P_{2 \infty}}{P_{10}+P_{20}-P_{1 \infty}-P_{2 \infty}} \\
= & \frac{\left[P_{1}(t)-P_{1 \infty}\right] /\left(P_{10}-P_{1 \infty}\right)}{1+\left(P_{20}-P_{2 \infty}\right) /\left(P_{10}-P_{1 \infty}\right)} \\
+ & \frac{\left[P_{2}(t)-P_{2 \infty}\right] /\left(P_{20}-P_{2 \infty}\right)}{\left(P_{10}-P_{1 \infty}\right) /\left(P_{20}-P_{2 \infty}\right)+1} \\
= & \frac{\zeta}{1+\zeta} \frac{P_{1}(t)-P_{1 \infty}}{P_{10}-P_{1 \infty}}+\frac{1}{1+\zeta} \frac{P_{2}(t)-P_{2 \infty}}{P_{20}-P_{2 \infty}} \\
= & \lambda \frac{P_{1}(t)-P_{1 \infty}}{P_{0}-P_{1 \infty}}+(1-\lambda) \frac{P_{2}(t)-P_{2 \infty}}{P_{0}-P_{2 \infty}} \\
= & \lambda \exp \left(-k_{1} \cdot t\right)+(1-\lambda) \exp \left(-k_{2} \cdot t\right)
\end{aligned}
$$

where, $Q_{r}$ is the decreasing percentage of gas pressure; $P_{1}(t), P_{2}(t), P_{10}, P_{20}, P_{1 \infty}$ and $P_{2 \infty}$ are the gas pressures in intact coal and tectonically deformed coal at times $t, t_{0}$ and 

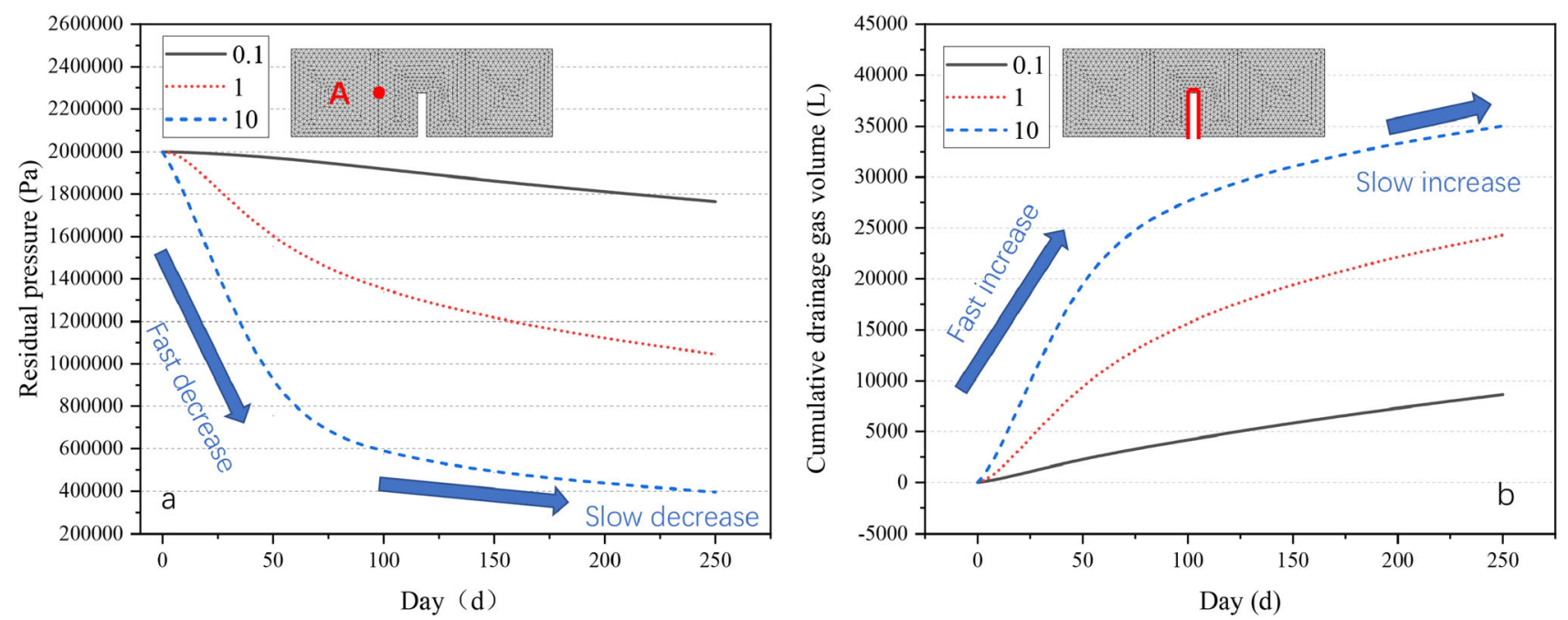

Fig. 6 Residual gas pressure at Point $A$ and cumulative gas drainage volume for whole area with different permeability ratios

$t_{\infty}$, respectively; $\lambda$ is the contribution from intact coal to the decrease of gas pressures, $\lambda=\zeta /(1+\zeta) ; \zeta$ is a constant, $\zeta=\left(P_{20}-P_{2 \infty}\right) /\left(P_{10}-P_{1 \infty}\right)$; and $k_{1}$ and $k_{2}$ are the firstorder kinetic constants for intact coal and tectonically deformed coal, respectively.

Table 2 displays the fitting results of data obtained in Fig. 6a using Eq. (14). In Case 1, the fitting results show a single-phase characteristic of a zero contribution from intact coal (Zone II with a high permeability). Moreover, the first-order kinetic constants fitted for the two systems are of the same value $\left(4.9 \times 10^{-4}\right)$, with an equally slow rate of mass transport. In Case 2, the contribution from intact coal rises to $47 \%$, almost equal to the contribution from tectonically deformed coal (53\%). With respect to the kinetic constant, $k_{1}$ is about two orders of magnitude larger than $k_{2}$. In Case 3 , the fitting results exhibit a clear dualphase characteristic. The contribution from intact coal is about 4 times larger than that from tectonically deformed coal. Besides, $k_{1}\left(2.5 \times 10^{-2}\right)$ is much larger than $k_{2}$ $\left(1.0 \times 10^{-4}\right)$.

Figure $6 \mathrm{~b}$ shows the cumulative gas drainage volume by taking the surface integral of gas pressure. When $k_{\mathrm{II}} / k_{\mathrm{I}}=10$, the curve is of the largest value and the greatest initial slope. As $k_{\mathrm{II}} / k_{\mathrm{I}}$ decreases to 0.1 , the curve, which approximates a straight line, is of the smallest value and the smallest initial slope. It can be inferred that, if the initial gas pressure is the same, completing gas drainage in the studied area consumes the longest time for Case 1 and the shortest time for Case 3. Thereby, it is suggested to design proper drainage methods for different gas occurrence conditions. For the situation in Case 1, longer drainage time, lower drainage pressure and smaller borehole spacing should be arranged in hope of achieving a satisfactory drainage effect.

\section{Drainage method optimization for coal with tectonically deformed sub-layers}

As revealed by the above analysis on gas drainage difficulties in coal seams with different combinations of tectonically deformed sub-layers and intact sub-layers, proper drainage methods should be adopted to ensure a satisfactory gas drainage volume in a fixed period, so that underground mining can be carried out at the scheduled rate. The drainage methods can be divided into two categories: commonly used drainage methods and enhanced drainage methods. The former, such as boreholes along the seam and boreholes crossing the seam, require longer drainage time, lower drainage pressure, smaller borehole spacing, larger borehole radius, etc., to achieve a better drainage performance. However, if these methods are not effective or

Table 2 Fitting results using Eq. (13)

\begin{tabular}{lllllll}
\hline Case & $\lambda$ & $1-\lambda$ & $k_{1}$ & $k_{1}$ & $R^{2}$ & Characteristic \\
\hline 1 & 0 & 1 & $4.9 \times 10^{-4}$ & $4.9 \times 10^{-4}$ & 0.9916 & Single-phase \\
2 & 0.47 & 0.53 & $1.1 \times 10^{-2}$ & $2.8 \times 10^{-4}$ & 0.9914 & Transition \\
3 & 0.79 & 0.21 & $2.5 \times 10^{-2}$ & $1.0 \times 10^{-4}$ & 0.9864 & Dual-phase \\
\hline
\end{tabular}




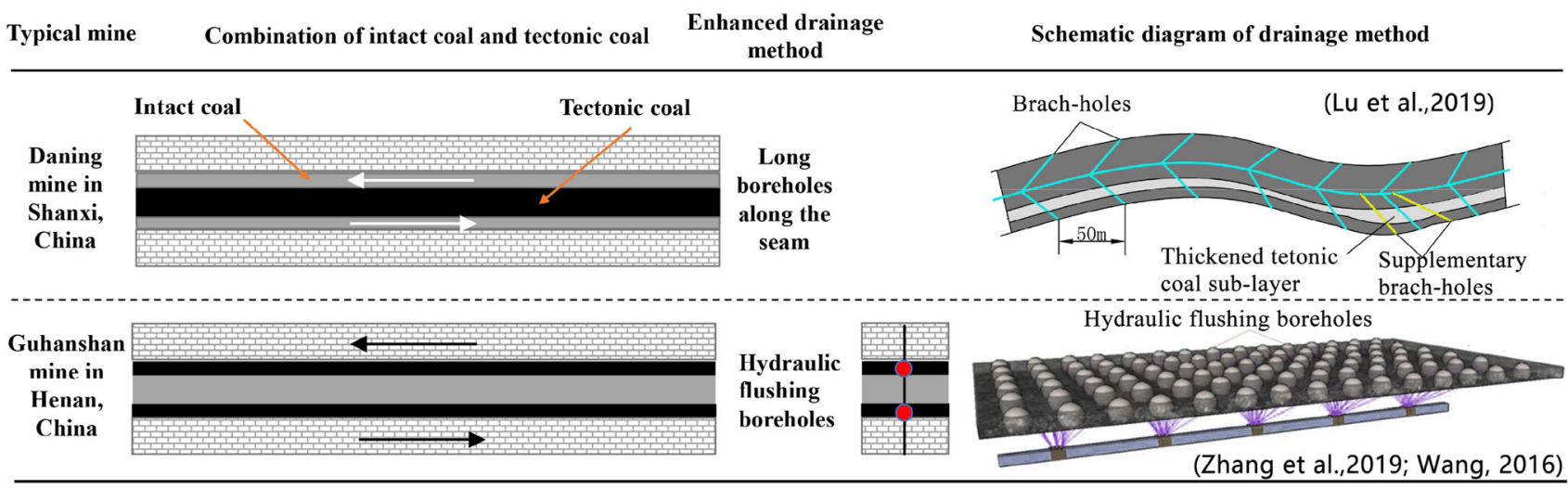

Fig. 7 Schematic diagram of drainage methods used in Daning Coal Mine and Guhanshan Coal Mine, China (Lu et al. 2019a, b; Wang 2016; Zhang et al. 2017)

economically allowable, enhanced drainage methods, such as long boreholes along the seam and hydraulic flushing boreholes, should be adopted to drain gas.

Figure 7 illustrates the schematic diagram of drainage methods used in Daning Coal Mine in Shanxi Province and Guhanshan Coal Mine in Henan Province, China. In Daning Coal Mine that possesses a typical "intact-tectonically deformed-intact" coal combination, long boreholes along the seam were constructed to drain gas in coal seams. The long boreholes can cover a huge area of coal seam and enhance coal permeability by means of initial water injection, conducing to efficient gas drainage in soft coal. Moreover, for the thickened tectonic sub-layers, branchholes were supplemented to promote the gas drainage performance.

In Guhanshan Coal Mine which has a typical "intacttectonically deformed" coal combination ("Tectonically deformed-intact-tectonically deformed" coal combination also exists locally.), a newly developed method of hydraulic flushing boreholes was applied to gas drainage in tectonically deformed sub-layers. These boreholes can enhance the coal permeability and the drainage radius in targeted places by flushing the soft tectonically deformed coal with high-pressure water. After applying the hydraulic flushing technology, the permeability difference between tectonic sub-layers and intact sub-layers is reduced, gradually forming a combination type described in Case 2 . Accordingly, the pressure decay curves change from dualstage ones to nearly one-stage ones. Figure 8 discloses a comparison between gas concentrations in hydraulic flushing boreholes and ordinary boreholes in literature. The gas concentration in ordinary boreholes falls at distinct rates in two stages (the fast stage and the slow stage), while that in hydraulic flushing boreholes declines as a smooth single-stage curve instead of showing dual-stage characteristics. Meanwhile, compared with the gas concentration in ordinary boreholes, that in hydraulic flushing boreholes

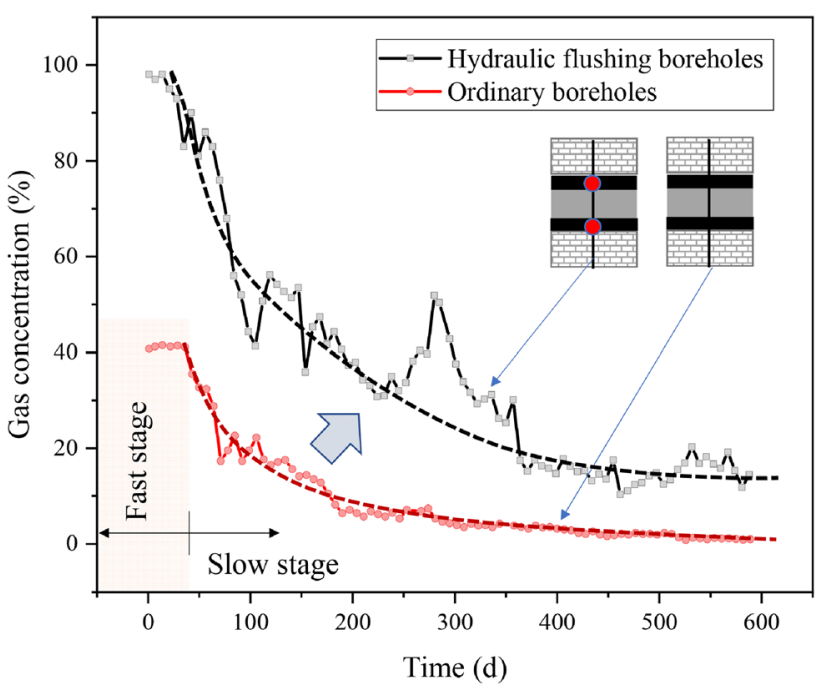

Fig. 8 Curves of gas concentration in hydraulic flushing boreholes and ordinary boreholes (Zhang et al. 2019)

corresponds to a reduced tangent curve slope and dramatically increased values, suggesting that shorter drainage time is needed if the gas volume to be drained is fixed. The result verifies correctness of the abovementioned numerical analysis.

\section{Conclusions}

In this study, the gas pressure distributions in layered coal seams consisting of tectonically deformed sub-layers and intact sub-layers were analyzed. The main conclusions are:

(1) Different combinations of tectonically deformed coal and intact coal determine the varying pressure distributions in coal seams. In Case 1 where $k_{\mathrm{II}} / k_{\mathrm{I}}=$ 0.1 , gas pressure mainly decreases around the borehole. The shapes of gas pressure decay in the 
high-permeability zone are nearly parallel straight lines, while those in the low-permeability zone are curves with large tangency slopes. In Case 2 where $k_{\mathrm{II}} k_{\mathrm{I}}=1$, the area of pressure decay expands, and the gas pressure distribution curves are distributed in a single-butterfly shape. In Case 3 where $k_{\mathrm{II}} / k_{\mathrm{I}}=10$, a clear partition line can be observed, and the curves are distributed in a dual-butterfly shape.

(2) The simulated gas drainage curve varies from a single-stage line to a dual-stage curve as the permeability ratio $k_{\mathrm{II}} / k_{\mathrm{I}}$ grows. For the smallest $k_{\mathrm{II}} /$ $k_{\mathrm{I}}$, it takes the longest time to drain all the gas in the studied area. Therefore, longer drainage time, lower drainage pressure and smaller borehole spacing or other enhanced drainage methods should be employed for achieving a satisfactory drainage effect.

(3) In-situ gas drainage data for hydraulic flushing boreholes and ordinary boreholes exhibit a clear dual-stage characteristic for the coal seam with tectonically deformed sub-layers and a single-stage characteristic for the permeability-enhanced coal seam, which verifies correctness of the simulated pressure decay curves.

Acknowledgements The authors are grateful to the financial support from the National Science Foundation of China (Nos. 51904311, 51874314), the Beijing Municipal Natural Science Foundation (8194072) and the Fundamental Research Funds for the Central Universities (2019QY02), the State Key Laboratory Cultivation Base for Gas Geology and Gas Control (Henan Polytechnic University) (WS2019A04). The Advanced Analysis \& Computational Center in CUMT was gratefully acknowledged for the help provided in numerical simulations. Comments by all anonymous reviewers are also appreciated.

Author contributions WZ: Conceptualization; Methodology; Software; Writing-Original Draft. KW: Supervision; Writing-Review \& Editing. RZ: Validation. HD: Visualization. ZL: Visualization. FA: Software.

Funding National Science Foundation of China (Nos. 51904311, 51874314). Beijing Municipal Natural Science Foundation (8194072). Fundamental Research Funds for the Central Universities (2019QY02). State Key Laboratory Cultivation Base for Gas Geology and Gas Control (Henan Polytechnic University) (WS2019A04).

\section{Compliance with ethical standards}

Conflict of interest The authors declare that they have no known competing financial interests or personal relationships that could have appeared to influence the work reported in this paper.

Open Access This article is licensed under a Creative Commons Attribution 4.0 International License, which permits use, sharing, adaptation, distribution and reproduction in any medium or format, as long as you give appropriate credit to the original author(s) and the source, provide a link to the Creative Commons licence, and indicate if changes were made. The images or other third party material in this article are included in the article's Creative Commons licence, unless indicated otherwise in a credit line to the material. If material is not included in the article's Creative Commons licence and your intended use is not permitted by statutory regulation or exceeds the permitted use, you will need to obtain permission directly from the copyright holder. To view a copy of this licence, visit http://creativecommons. org/licenses/by/4.0/.

\section{References}

Airey EM (1968) Gas emission from broken coal. An experimental and theoretical investigation. Int $J$ Rock Mech Mining Sci \& Geomech Abstr 5:475-494. https://doi.org/10.1016/01489062(68)90036-3

An F, Cheng Y, Wang L, Li W (2013) A numerical model for outburst including the effect of adsorbed gas on coal deformation and mechanical properties. Comput Geotech 54:222-231. https://doi. org/10.1016/j.compgeo.2013.07.013

Black DJ (2019) Review of coal and gas outburst in Australian underground coal mines. Int J Mining Sci Technol. https://doi. org/10.1016/j.ijmst.2019.01.007

Busch A, Gensterblum Y, Krooss BM, Littke R (2004) Methane and carbon dioxide adsorption: diffusion experiments on coal: upscaling and modeling. Int $\mathrm{J}$ Coal Geol 60:151-168

Cheng Y, Pan Z (2020) Reservoir properties of Chinese tectonic coal: a review. Fuel 260:116350. https://doi.org/10.1016/j.fuel.2019. 116350

Fan L, Liu S (2018) Numerical prediction of in situ horizontal stress evolution in coalbed methane reservoirs by considering both poroelastic and sorption induced strain effects. Int J Rock Mech Min 104:156-164. https://doi.org/10.1016/j.ijrmms.2018.02.012

Fan L, Liu S (2019) Fluid-dependent shear slip behaviors of coal fractures and their implications on fracture frictional strength reduction and permeability evolutions. Int $\mathrm{J}$ Coal Geol 212:103235. https://doi.org/10.1016/j.coal.2019.103235

Geological Report of Guhanshan Mine (2015) Geological report of Guhanshan mine. Guhanshan Mine Henan Coking Coal Energy Co. Ltd., Henan

Gong B, Jiang Y, Chen L (2019) Feasibility investigation of the mechanical behavior of methane hydrate-bearing specimens using the multiple failure method. J Nat Gas Sci Eng 69:102915

Ju Y, Luxbacher K, Li X, Wang G, Yan Z, Wei M, Yu L (2014) Micro-structural evolution and their effects on physical properties in different types of tectonically deformed coals. Int J Coal Sci Technol 1:364-375. https://doi.org/10.1007/s40789-0140042-1

Liu S, Harpalani S (2013) Permeability prediction of coalbed methane reservoirs during primary depletion. Int J Coal Geol 113:1-10. https://doi.org/10.1016/j.coal.2013.03.010

Lu S, Wang C, Liu Q, Zhang Y, Liu J, Sa Z, Wang L (2019a) Numerical assessment of the energy instability of gas outburst of deformed and normal coal combinations during mining. Process Saf Environ 132:351-366. https://doi.org/10.1016/j.psep.2019. 10.017

Lu SQ, Zhang YL, Sa ZY, Si SF, Shu LY, Wang L (2019b). Damage-induced permeability model of coal and its application to gas predrainage in combination of soft coal and hard coal. Energy Sci Eng 7(4):1352-1367

Pan Z, Connell LD, Camilleri M, Connelly L (2010) Effects of matrix moisture on gas diffusion and flow in coal. Fuel 89:3207-3217

Wang S, Elsworth D, Liu J (2015) Rapid decompression and desorption induced energetic failure in coal. J Rock Mech 
Geotech Eng 7:345-350. https://doi.org/10.1016/j.jrmge.2015. 01.004

Wang W (2016) Coal breakage impact by high pressure rotary water jet and induced pressure relief and permeability enhancement by hydraulic flushing cavity: mechanism and application. Doctor, China University of Mining and Technology, Xuzhou

Wu X, Peng Y, Xu J, Yan Q, Nie W, Zhang T (2019) Experimental study on evolution law for particle breakage during coal and gas outburst. Int J Coal Sci Technol. https://doi.org/10.1007/s40789019-00284-1

Zhang H, Cheng Y, Liu Q, Yuan L, Dong J, Wang L, Qi Y, Wang W (2017) A novel in-seam borehole hydraulic flushing gas extraction technology in the heading face: enhanced permeability mechanism, gas flow characteristics, and application. J Nat Gas Sci Eng 46:498-514. https://doi.org/10.1016/j.jngse.2017. 08.022
Zhang R, Cheng Y, Yuan L, Zhou H, Wang L, Zhao W (2019) Enhancement of gas drainage efficiency in a special thick coal seam through hydraulic flushing. Int $J$ Rock Mech Min 124:104085. https://doi.org/10.1016/j.ijrmms.2019.104085

Zhao W, Cheng Y, Yuan M, An F (2014) Effect of adsorption contact time on coking coal particle desorption characteristics energy. Fuel 28:2287-2296. https://doi.org/10.1021/ef402093g

Zhao W, Cheng Y, Jiang H, Jin K, Wang H, Wang L (2015) Role of the rapid gas desorption of coal powders in the development stage of outbursts. J Natural Gas Sci Eng 28:491-501

Zhao W, Cheng Y, Pan Z, Wang K, Liu S (2019) Gas diffusion in coal particles: a review of mathematical models and their applications. Fuel 252:77-100. https://doi.org/10.1016/j.fuel.2019.04. 065

Zhi S, Elsworth D (2016) The role of gas desorption on gas outbursts in underground mining of coal. Geomech Geophys Geo-Energy Geo-Resour 2:1-21 